\title{
A Feasibility Study of Lavender Aromatherapy in an Awake Craniotomy Environment
}

\author{
Kailah Cathey \\ Nichole Gunyon \\ Nancy Chung \\ Nancy Conway \\ Diane Ames \\ Maharaj Singh \\ Amin B. Kassam \\ Richard A. Rovin
}

Follow this and additional works at: https://aah.org/jpcrr

Part of the Alternative and Complementary Medicine Commons, Integrative Medicine Commons, Nervous System Commons, Neurology Commons, Perioperative, Operating Room and Surgical Nursing Commons, Surgery Commons, and the Surgical Procedures, Operative Commons

\section{Recommended Citation}

Cathey K, Gunyon N, Chung N, Conway N, Ames D, Singh M, Kassam AB, Rovin RA. A feasibility study of lavender aromatherapy in an awake craniotomy environment. J Patient Cent Res Rev. 2020;7:19-30. doi: $10.17294 / 2330-0698.1716$

Published quarterly by Midwest-based health system Advocate Aurora Health and indexed in PubMed Central, the Journal of Patient-Centered Research and Reviews (JPCRR) is an open access, peer-reviewed medical journal focused on disseminating scholarly works devoted to improving patient-centered care practices, health outcomes, and the patient experience. 


\title{
A Feasibility Study of Lavender Aromatherapy in an Awake Craniotomy Environment
}

\author{
Kailah Cathey, ${ }^{1}$ Nichole Gunyon, MSN, ${ }^{2}$ Nancy Chung, PA-C, ${ }^{2}$ Nancy Conway, MS, CCAP, ${ }^{3}$ \\ Diane Ames, DNP, CCAP, ${ }^{3}$ Maharaj Singh, PhD, ${ }^{4}$ Amin B. Kassam, MD, ${ }^{2}$ Richard A. Rovin, MD $^{2}$ \\ ${ }^{1}$ Leuzinger High School, Lawndale, CA; ${ }^{2}$ Aurora Neuroscience Innovation Institute, Aurora Health Care, \\ Milwaukee, WI; ${ }^{3}$ Integrative Medicine, Aurora Health Care, Milwaukee, WI; ${ }^{4}$ Aurora Research Institute, \\ Aurora Health Care, Milwaukee, WI
}
Purpose Integrative medicine interventions are needed for awake craniotomies, as many patients experience anxiety. Lavender aromatherapy significantly reduces anxiety or pain in a variety of surgical procedures. This feasibility study used lavender aromatherapy during awake craniotomies to determine the number of patients who would consent and complete the study, the technicality of lavender aromatherapy use, and acceptance by operating room (OR) staff.
Methods We approached 40 consecutive patients ( $\geq 18$ years old). Exclusion criteria were pulmonary issues or sensitivity to lavender. Outcome measures in consented patients were enrollment and completion rates, anxiety and pain as measured by the Visual Analog Scale for Anxiety (VAS-A) and Visual Analog Scale for Pain (VAS-P), and satisfaction with pain control using the Patient Opinion of Pain Management (POPM) survey.

Results Of the 40 patients approached, 4 declined participation or had their surgery cancelled. Of the remaining 36, 4 required increased sedation during surgery and 1 was unable to detect lavender. Thus, 31 patients $(77.5 \%)$ completed the study. VAS-A and VAS-P scores trended lower after lavender inhalation, but the difference did not reach statistical significance. There was a slight increase in VAS-P score at the OR1 time point. Expectancy for reduction in both anxiety and pain were not significantly different. Improvement in anxiety also was not different, while improvement in pain trended lower $(\mathrm{P}=0.025)$. POPM results indicated the majority of patients were either "satisfied" or "very satisfied" with pain management.

Conclusions This study demonstrated $77.5 \%$ completion and the ability to integrate lavender aromatherapy into the OR. Thus, we plan to conduct a randomized clinical trial to assess efficacy of lavender aromatherapy. (J Patient Cent Res Rev. 2020;7:19-30.)

Keywords awake craniotomy; lavender; aromatherapy; feasibility study; pain; anxiety; neurosurgery

wake craniotomy during brain surgery
permits monitoring of speech, motor, and
sensory function. This procedural approach is increasingly utilized for its several advantages over a traditional general anesthetic technique. These advantages include minimization of new neurological

Correspondence: Nancy Conway, MS, CCAP, Aurora Integrative Medicine, Outpatient Health Center, 1020 N. 12th Street, 4th Floor, Milwaukee, WI 53233 (nancy.conway@aurora.org) deficits, as the patient is continuously assessed by both physical examination and neurocognitive testing, ${ }^{1}$ a reduction in operating time, ${ }^{2}$ and minimal postoperative recovery and decreased length of hospital stay. ${ }^{3}$

Although many patients tend to tolerate awake cranial surgery well, recent studies have found that roughly $30 \%$ of patients experience moderate to severe pain and anxiety, ${ }^{4} 50 \%$ report moderate fear, and $11 \%$ report severe fear. ${ }^{5}$ Therefore, alternative methods to mitigate pain and anxiety are needed. Interventions that would alleviate pain and anxiety during an awake craniotomy 
without interfering with the neurocognitive exam are limited. For example, a 1998 glioma study utilizing hypnosis was found to have a favorable psychological impact. ${ }^{6}$ However, hypnosis also has been shown to inhibit left frontal lobe function and therefore influence results of neurocognitive exams. ${ }^{7}$

There is a growing body of literature related to the use of lavender aromatherapy as an anxiolytic agent. A study of 150 patients randomized into standard of care, standard of care plus an unscented "sham" aromatherapy, or standard of care plus lavender aromatherapy found a significant decrease in anxiety when transferred to the operating room, per the Visual Analog Scale for Anxiety (VAS-A), in the lavender aromatherapy group. ${ }^{8}$ Similarly, 93 women awaiting breast surgery were randomized to receive lavender aromatherapy or unscented oil. Anxiety, as measured by the State-Trait Anxiety Inventory, was significantly reduced in the lavender group. ${ }^{9}$

There is also evidence to suggest that lavender aromatherapy has an analgesic effect. Several studies of patients with divergent procedures, including breast biopsies, gastric banding, tonsillectomies, cesarean sections, and coronary artery bypass grafts, all tested whether lavender aromatherapy reduced pain intensity, using the Visual Analog Scale for Pain (VAS-P), and changed narcotic requirements. ${ }^{10-14}$ In the patients receiving gastric banding or tonsillectomy, treatment with lavender aromatherapy reduced use of narcotics without a change in pain intensity, ${ }^{11,12}$ while in those receiving cesarean section or coronary bypass, there was a significant reduction in pain intensity with use of lavender aromatherapy. ${ }^{13,14}$ In addition, a meta-analysis of 12 studies reporting the use of aromatherapy to manage pain determined that lavender aromatherapy reduced pain on VAS-P. ${ }^{15}$

Based on these findings, we hypothesized that the use of lavender aromatherapy during awake cranial surgery could enhance patient comfort and therefore merited clinical evaluation. To our knowledge, lavender aromatherapy has not been utilized in an awake craniotomy setting. Thus, this preparatory trial was designed to assess the feasibility of lavender aromatherapy intervention intraoperatively to evaluate the effects of lavender aromatherapy on anxiety and pain as well as improve satisfaction with pain control in patients undergoing awake cranial surgery. It was our intention that results from this feasibility study could be used to inform a subsequent randomized trial to assess efficacy of lavender aromatherapy.

\section{METHODS \\ Study Design}

This was a pilot single-arm clinical trial preparatory to a randomized trial. ${ }^{16,17}$ The study was approved by the Aurora Health Care (Aurora) institutional review board, and the U.S. Food and Drug Administration allowed the study to proceed without an Investigational New Drug requirement. This study is also listed on clinicaltrials.gov as "Feasibility of Aromatherapy in an Awake Craniotomy Environment" (https://clinicaltrials.gov/ct2/show /NCT03328143?term=aromatherapy\&cond=awake + craniotomy\&rank=1).

Primary objective was feasibility with several endpoints: 1) Determine the percentage of patients who would consent to participate; 2) Determine the percentage of patients who would then complete the study following consent to participate; 3) Determine the technical aspects of administering lavender aromatherapy in the operating theater; 4) Determine the acceptance of lavender aromatherapy by multiple anesthesiologists, neurosurgeons, neuropsychologists, neuropsychometrists, and nursing staff. Secondary objectives were to determine the impact of lavender aromatherapy on pain and anxiety and to determine patient satisfaction with pain control during awake cranial surgery.

Outcome measures were enrollment and completion rates, anxiety as measured by VAS-A (Figure 1A), ${ }^{18,19}$ pain intensity as measured by VAS-P (Figure 1B), ${ }^{20}$ and satisfaction with pain control as measured by the Patient Opinion of Pain Management (POPM) survey. ${ }^{21}$ These three instruments are further detailed within the "Subjective Assessment Tools" subsection.

\section{Recruitment of Potential Research Subjects}

Consecutive eligible patients were asked during their preoperative evaluation if they would like to participate in this clinical trial. This conversation took place either in the outpatient clinic or the inpatient 


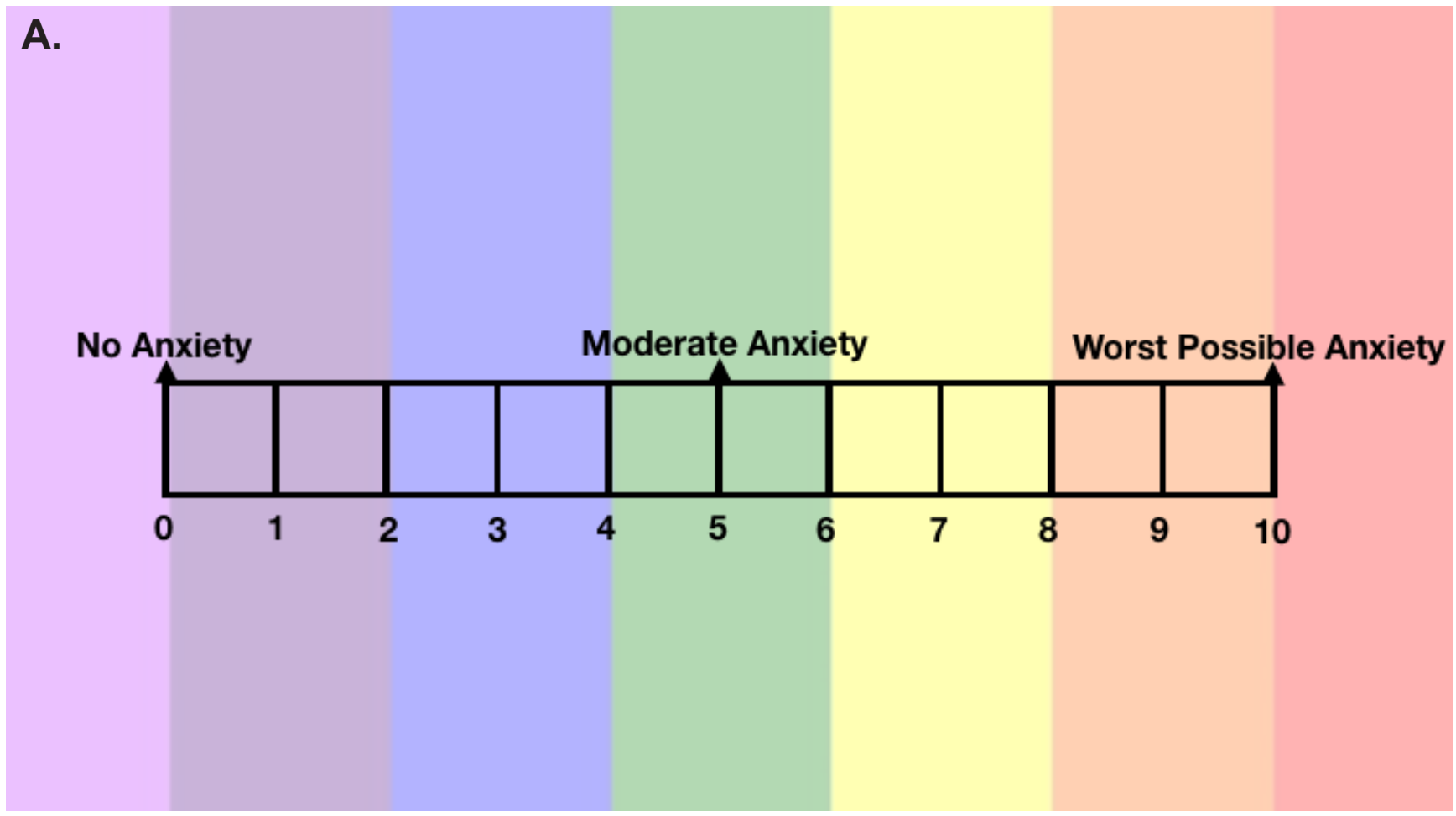

On a scale from $0-10$, how anxious are you right now?

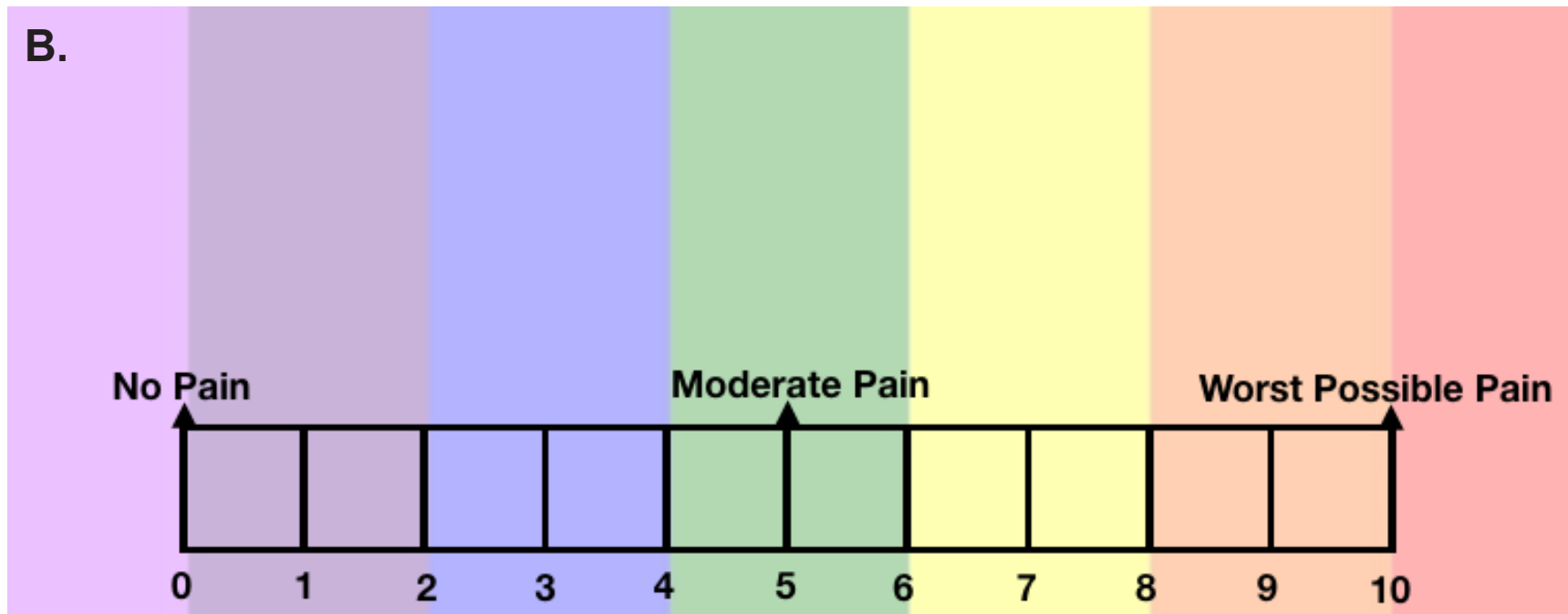

On a scale from $0-10$, how much pain do you have right now?

Figure 1. Visual analogue scales for anxiety and pain. Patients were asked to score their anxiety (A) and pain (B) before, during, and after surgery. 
setting. Participating patients received Aurora-created educational material regarding aromatherapy and lavender. Planned enrollment was 40 patients.

Any adult patient (ie, $\geq 18$ years of age) undergoing awake cranial neurosurgery was eligible for inclusion. At Aurora, awake cranial surgery is primarily used for adult patients with benign or malignant extraaxial and intra-axial brain tumors. Exclusion criteria were allergy or sensitivity to lavender (Lavandula angustifolia); aversion to the lavender scent, which included unpleasant associated memory in patients who received a test dose of lavender scent administered through a nasal inhaler; history of asthma or chronic obstructive pulmonary disease; history of contact dermatitis following exposure to cosmetic fragrances; and pregnancy.

\section{Study Procedures}

The lavender aromatherapy trial protocol was developed in conjunction with Aurora's integrative medicine department and certified clinical aromatherapy practitioners (CCAP). Institutional policy on aromatherapy (Aurora Policy 2032, dated July 2012) provided additional guidance.

After informed consent was obtained, subjects were given a brief expectancy questionnaire (Figure 2) to delineate their preoperative expectations of outcomes from their participation in the trial. The same

\section{Preprocedure - Anxiety}

1. At this point, how successful do you think aromatherapy will be in reducing your anxiety symptoms? (on a scale from 0 to 10 )
0
23
$4 \underset{\text { (somewhat) }}{5} 6$
$\begin{array}{lll}7 & 8 & 9\end{array}$
10
(not at all)
(very)

2. By the end of the study, how much do you think your anxiety will improve? (in percent) $\begin{array}{lllllllllll}0 \% & 10 \% & 20 \% & 30 \% & 40 \% & 50 \% & 60 \% & 70 \% & 80 \% & 90 \% & 100 \%\end{array}$

\section{Preprocedure - Pain}

1. At this point, how successful do you think aromatherapy will be in reducing your pain symptoms? (on a scale from 0 to 10 )

\begin{tabular}{ccccccccccc}
0 & 1 & 2 & 3 & 4 & 5 & 6 & 7 & 8 & 9 & 10 \\
(not at all) & & & \multicolumn{1}{c}{$\begin{array}{c}\text { (somewhat) } \\
\text { (very) }\end{array}$}
\end{tabular}

2. By the end of the study, how much do you think your pain will improve? (in percent)

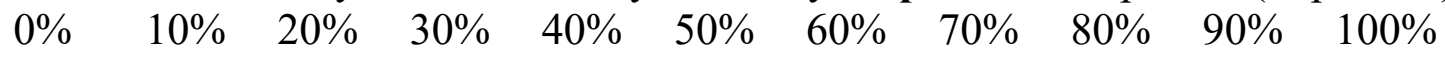

\section{Postprocedure - Anxiety}

1. How successful was aromatherapy in reducing your anxiety? (on a scale from 0 to 10 )

2. By the end of the study, how much did your anxiety improve? (in percent)

Postprocedure - Pain

1. How successful was aromatherapy in reducing your pain? (on a scale from 0 to 10)

2. By the end of the study, how much did your pain improve? (in percent)

Figure 2. Expectancy questionnaire. 
questionnaires were administered after surgery, upon the patient's arrival to the neurosurgical intensive care unit (Neuro-ICU).

Participating patients received standard-of-care intraoperative analgesic and anxiolytic management plus lavender aromatherapy. Lavender scent was administered via nasal inhaler (Figure 3). The lavender essential oil (Elizabeth Van Buren, Inc., Santa Cruz, CA), base oil (Elizabeth Van Buren, Inc.), and nasal inhaler (Bulk Apothecary, Aurora, $\mathrm{OH}$ ) were provided by the integrative medicine department to ensure standardization across all patients. The nasal inhaler was prepared with $15 \mathrm{gtts}$ (drops) of lavender essential oil and 4 gtts (drops) of the base oil (grapeseed oil). A CCAP from integrative medicine provided training on the delivery of lavender aromatherapy to all study team members. This person consulted on the participation of the first 3 subjects and was present in the operating room (OR) to oversee administration of lavender aromatherapy. The CCAP also was available for consultation during the course of the study, as needed.

A dedicated OR nurse, neuropsychologist, or neuropsychometrist oversaw administration of lavender aromatherapy to subjects. They monitored the subject during study participation and were prepared to discontinue the trial if they felt continued

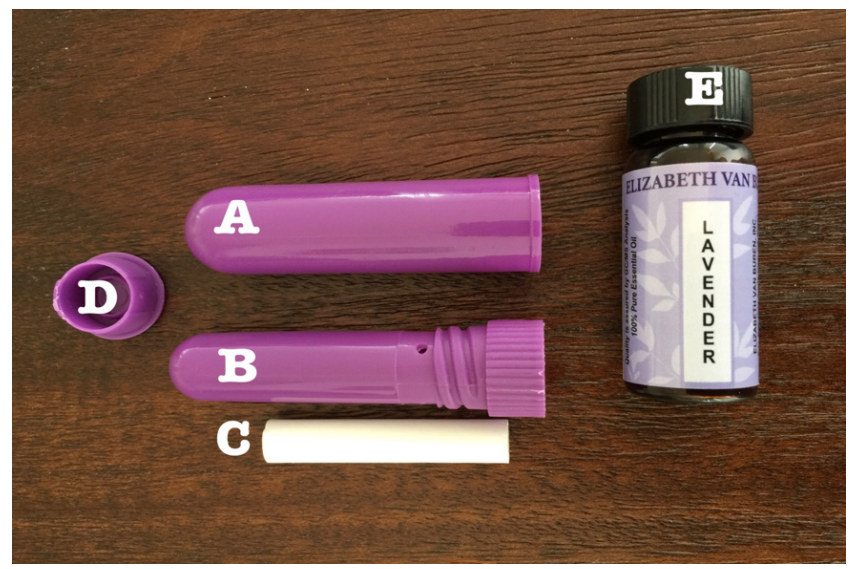

Figure 3. Components of the lavender inhaler (Bulk Apothecary, Aurora, OH). A: Outer sealed sheath. B: Inner inhaler. This is removed from the outer sheath to provide focal inhalation of scent. C: Cotton wick to which the lavender and base oils are applied. It is inserted into $(B)$ and sealed with end cap (D). E: The lavender essential oil (Elizabeth Van Buren, Inc., Santa Cruz, CA). participation was detrimental to the patient. Lavender aromatherapy was administered for up to 5 minutes using the nasal inhaler at designated time points (preoperative, induction) and every 30 minutes during the surgery (Figure 4). OR1 was the time at which surgery was initiated, every 30 -minute interval thereafter received a consecutive number (OR2-OR5). Although OR personnel administered the aromatherapy most of the time, some patients were able to and chose to self-administer. Additional lavender aromatherapy treatments were provided at any time on request. During non-use periods, the nasal inhaler was capped and sealed.

If the subject was unable to verbally request the research team member to hold the nasal inhaler under their nose, the subject's participation in the study was terminated. Additionally, subjects were free to discontinue administration of aromatherapy at any time during their participation in the study. The timing and reason of discontinuation of lavender aromatherapy was recorded.

\begin{tabular}{|c|c|c|c|}
\hline Time Point & VAS-A & VAS-P & POPM \\
\hline Pre-op hold & $\mathrm{X}$ & $\mathrm{X}$ & \\
\hline Induction room & $\mathrm{X}$ & $\mathrm{X}$ & \\
\hline Every 30 minutes: & & & \\
\hline OR1 & $\mathrm{X}$ & $\mathrm{X}$ & \\
\hline OR2 & $\mathrm{X}$ & $\mathrm{X}$ & \\
\hline OR3 & $\mathrm{X}$ & $\mathrm{X}$ & \\
\hline OR4 & $\mathrm{X}$ & $\mathrm{X}$ & \\
\hline OR5 & $\mathrm{X}$ & $\mathrm{X}$ & \\
\hline Neuro-ICU & & & $\mathrm{X}$ \\
\hline
\end{tabular}

Figure 4. Use of Visual Analog Scale for Anxiety (VAS-A), Visual Analog Scale for Pain (VAS-P), and Patient Opinion of Pain Management (POPM) assessment tools at various study time points. Patients were given lavender aromatherapy before the operation, in the induction room, in the OR at the start of surgery (OR1), and every 30 minutes thereafter (OR2-OR5). The POPM was administered to patients in the neurosurgical intensive care unit (Neuro-ICU). 


\section{Subjective Assessment Tools}

The expectancy questionnaire consisted of 4 questions (2 regarding anxiety and 2 regarding pain) asked and answered before surgery and asked and answered after surgery (Figure 2). For each outcome, the first question asked the patient to evaluate how well they expected their anxiety or pain to be reduced with lavender aromatherapy. The second question asked the patient to evaluate to what degree they expected their anxiety or pain to be improved with lavender aromatherapy (Figure 2, Preprocedure). Patients were then asked to evaluate how well their anxiety or pain was actually reduced or improved following surgery (Figure 2, Postprocedure).

VAS-A and VAS-P scores were obtained on the traditional 11-point scale, which ranges from 0 to 10 (Figure 1). Participating patients were asked to rate their pain and anxiety before surgery (preop), during induction (induction), at the start of surgery (OR1), and at 30-minute intervals (OR2-OR5) (Figure 4).

The POPM tool employs a 5-point Likert scale for the query "How satisfied are you with your pain treatment overall?" This question was asked of subjects upon arrival to the Neuro-ICU. Response choices were "Very Dissatisfied," "Dissatisfied," "Uncertain," "Satisfied," and "Very Satisfied."

\section{Statistical Plan}

This feasibility study consisted of 40 participants. Enrollment rate and trial completion rate were calculated. Demographic characteristics were noted using appropriate descriptive statistics for all categorical and continuous variables. A total of 31 patients completed the study and were included for analyses. As both VAS-A and VAS-P were assessed multiple times for the same patients, mean scores of these measures were compared using the repeated measures analysis of variance (ANOVA), including multivariate analysis of variance (MANOVA) tests in the general linear model. Expectancy questionnaire responses were analyzed using a 2-sided, paired t-test. Mean POPM scores were compared using an independent t-test. Predefined subgroups included gender, primary vs metastatic tumor, and age by decade. An alpha of 0.05 was used for all statistical tests, and all analyses were done using SAS $^{\circledR} 9.4$ (SAS Institute Inc., Cary, NC).

\section{Adverse Event Monitoring}

This trial used the U.S. Department of Health and Human Services' Common Terminology Criteria for Adverse Events, Version 4.0 (published May 28, 2009; revised June 14, 2010) for toxicity and adverse event reporting. Allergic, pulmonary, and gastrointestinal adverse events were recorded.

\section{RESULTS}

From April 4, 2018, to January 2, 2019, 40 patients were asked to enroll in this study; 3 declined (7.5\%). Patient characteristics are summarized in Table 1. All surgeries took place at Aurora St. Luke's Medical Center (Milwaukee, WI). Two anesthesiologists,

Table 1. Study Population Characteristics

\begin{tabular}{lc}
\hline Characteristic & $\mathbf{n}^{*}$ \\
\hline Gender & 19 \\
Male & 21 \\
Female & 60 years \\
Mean age & \\
Pathology & 1 \\
Atypical meningioma & 12 \\
High-grade glioma & 3 \\
Low-grade glioma & 3 \\
Meningioma & 7 \\
Metastasis & 4 \\
Other & 1 \\
Sarcoma & \\
Position & 1 \\
Half lateral & 11 \\
Lateral decubitus, left up & 4 \\
Lateral decubitus, right up & 2 \\
Supine & 14 \\
Supine, bump under shoulder & 10 \\
Self-description & 21 \\
A very anxious person & \\
A not very anxious person & \\
A high pain tolerance & 10 \\
A low pain tolerance & \\
\hline
\end{tabular}

*Note: The 40 patients asked to participate in the study make up gender and age categories; the 31 patients who completed the study comprise the total for pathology, position, and self-description categories. 
3 neurosurgeons, 2 neuropsychologists, 2 neuropsychometrists, and 1 circulating registered nurse attended the patients in the OR.

Of the 40 patients approached, 36 consented to participate in the trial. Four participants were unable to complete the intraoperative portion of the trial due to increased sedation needs, and 1 participant was unable to smell the lavender during the surgery, although that person had not met the exclusion criteria prior to surgery. The inability to smell the lavender was felt to be related to competing smells within the OR as opposed to an inhaler failure, as OR personnel were able to detect the lavender scent. In total, 31 patients $(77.5 \%$ of the 40 approached, $86.1 \%$ of the 36 who consented) completed all elements of the trial (Figure 5).

On an observational level, providing lavender aromatherapy to patients appeared to be seamlessly integrated into the neurocognitive exam and the aromatherapy protocol was vocally embraced by many members of the OR teams. When patients were asked if they preferred to receive lavender aromatherapy as needed or on a scheduled basis, $77 \%$ of patients preferred to receive inhalations on an as-needed basis compared with $23 \%$ who preferred the scheduled inhalations.

\section{Impact on Anxiety}

Mean scores for VAS-A before lavender aromatherapy were slightly higher than they were after aromatherapy at each of the inhalation times: preop, induction, OR1OR5 (Figure 6A). Time points beyond OR5 had fewer than 10 data points and therefore are not presented. The trend toward reduced anxiety after lavender aromatherapy did not reach statistical significance. There was little difference between patients' expected and experienced anxiety relief (Figure 7, blue bars).

\section{Impact on Pain and Pain Management}

Mean scores for VAS-P were the same or slightly higher before lavender aromatherapy compared to after inhalation (Figure 6B). Again, this did not reach statistical significance. A small increase in VAS-P was noted after lavender aromatherapy at the OR1 time point. The reason for this is unclear. There was little difference when patients were asked to rate their expected reduction in pain compared to actual

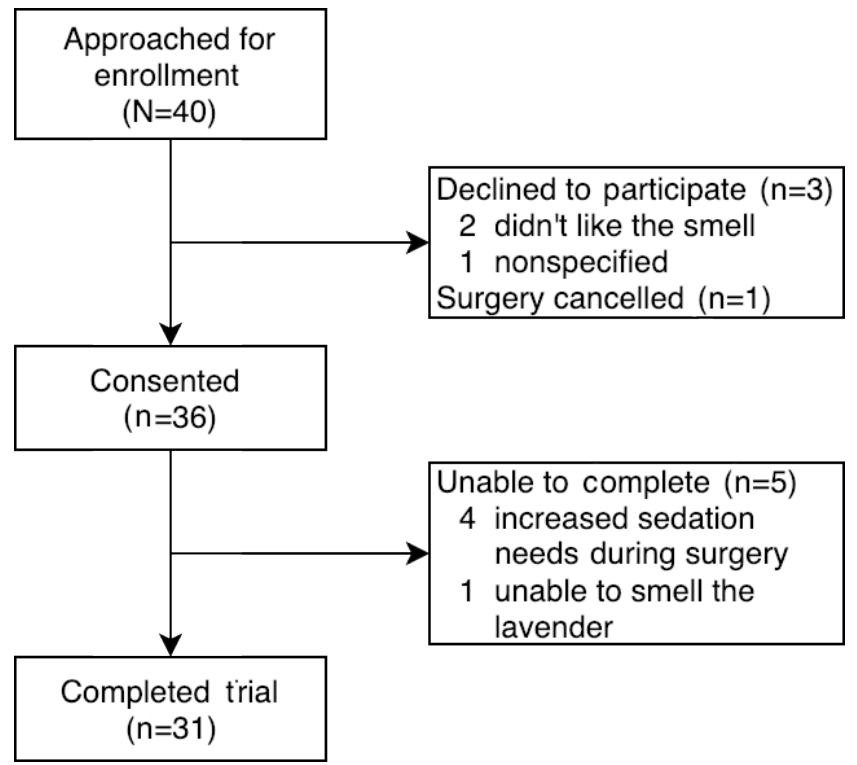

Figure 5. Consolidated Standards of Reporting Trials (CONSORT) diagram.

pain reduction (Figure 7A, red bars), but there was a significant drop in the amount of pain improvement (Figure 7B, red bars) compared to the expected improvement $(\mathrm{P}=0.025)$.

When POPM data were assessed, the majority of patients were either "Satisfied" or "Very satisfied" with their pain management (Figure 8).

\section{Adverse Events}

No immediate adverse events were noted. There were no toxicity reactions and no pulmonary events. One patient described unpleasant recall of the surgical procedure when exposed to lavender scent after surgery. There were no requests to discontinue lavender aromatherapy.

\section{DISCUSSION}

The neurosurgical OR is a complex environment. Moreover, there is a high level of coordination and collaboration needed between OR team members: neurosurgical, anesthesiology, neuropsychology, nursing, and technical support. For awake patients, there are additional challenges including the need for constant monitoring of comfort, anxiety, and 


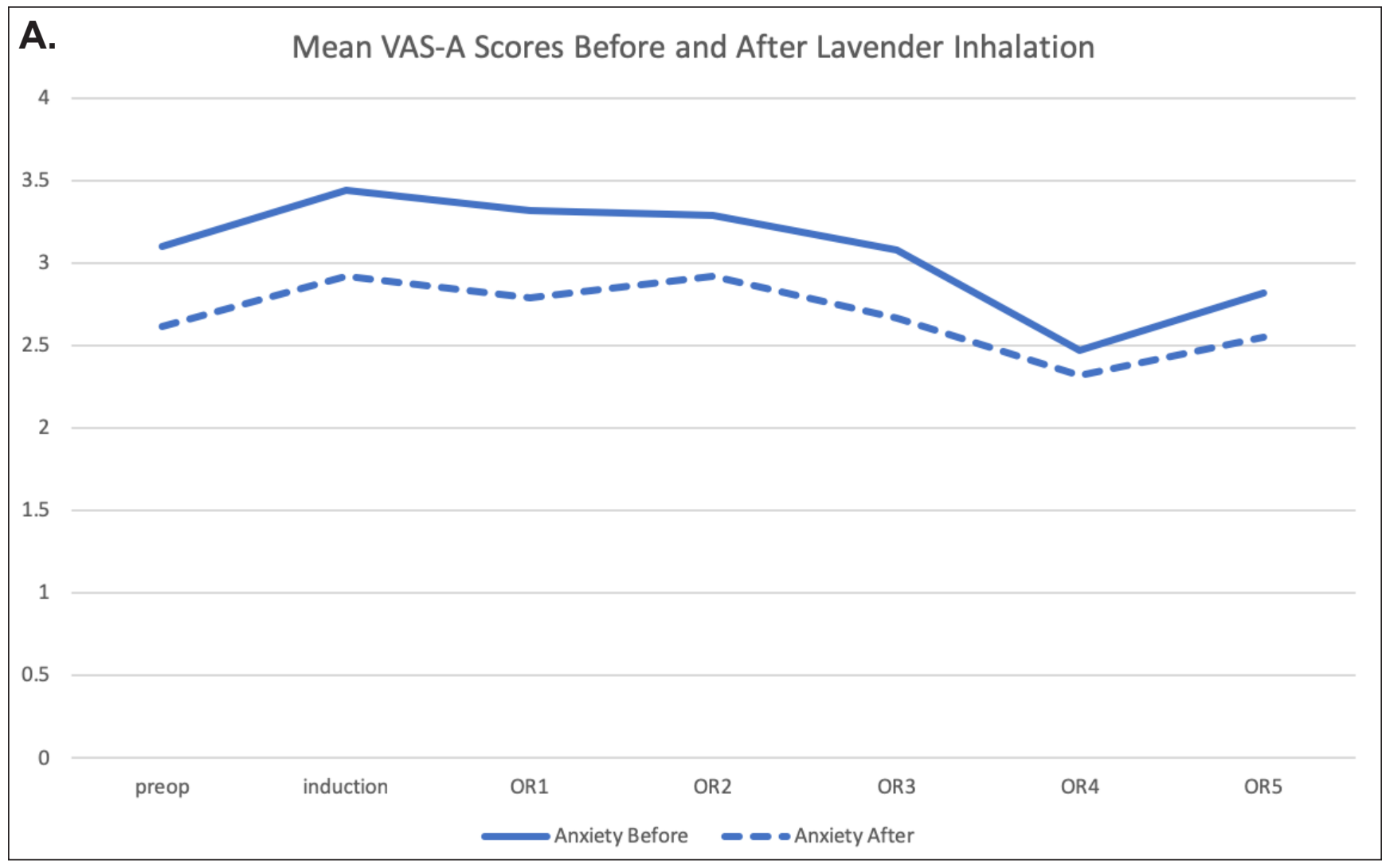

\section{B. Mean VAS-P Scores Before and After Lavender Inhalation}

4

3.5

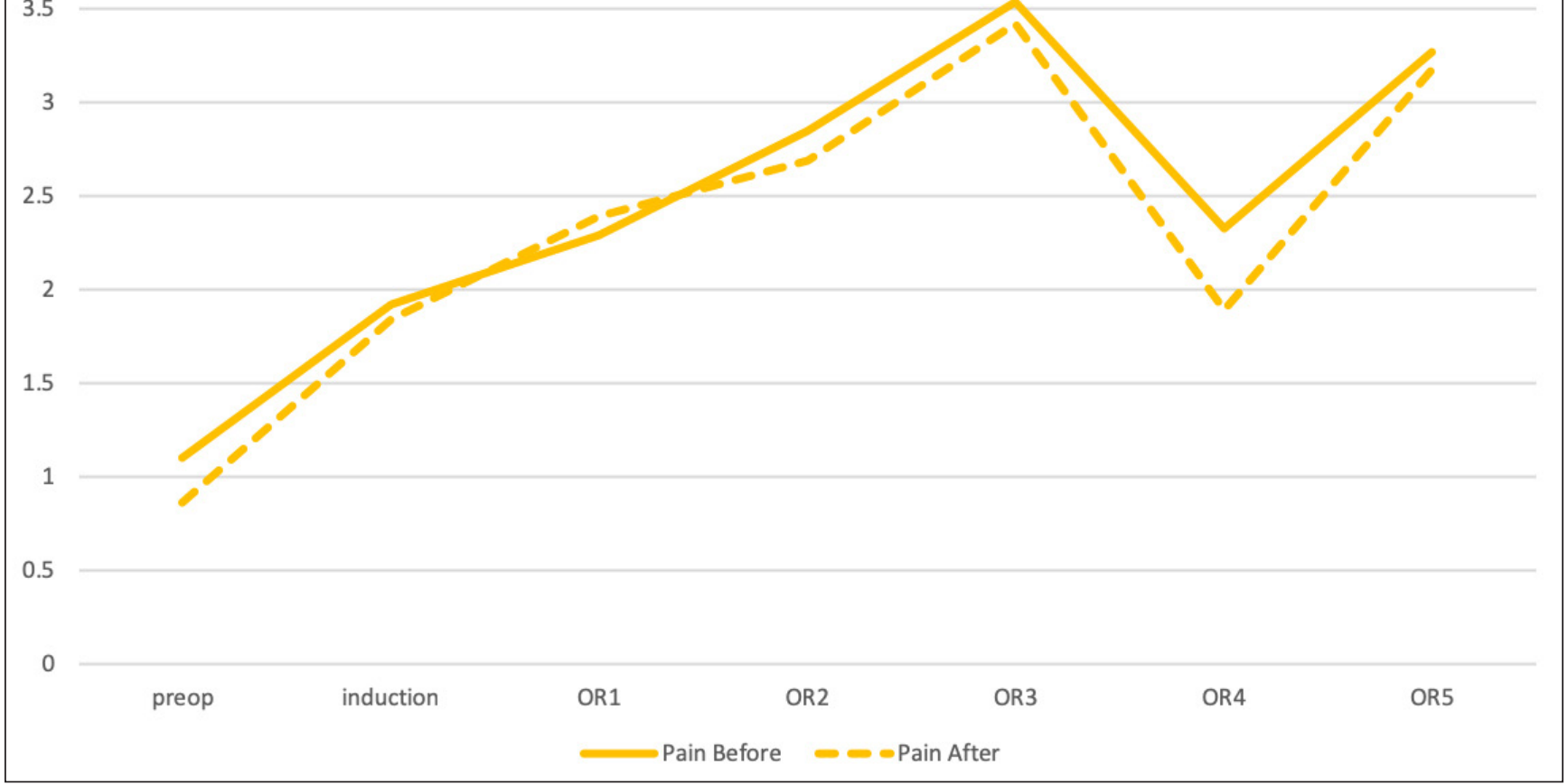

Figure 6. VAS-A (A) and VAS-P (B) scores, before and after lavender aromatherapy, at each implementation time point. The OR1 time point correlated with the start of surgery, with OR2-OR5 indicating 30-minute intervals between aromatherapy application. VAS-A, Visual Analog Scale for Anxiety; VAS-P, Visual Analog Scale for Pain. 


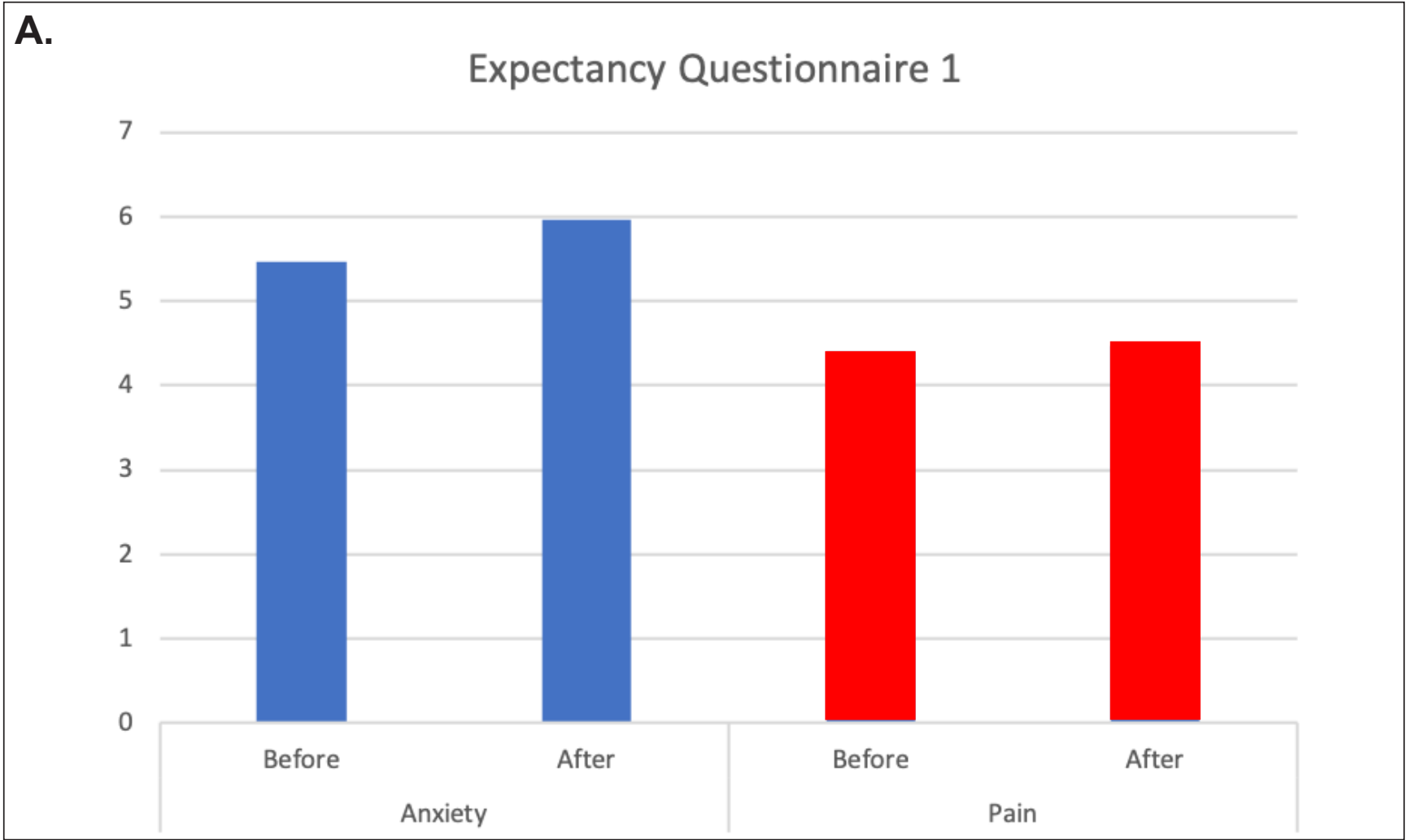

B.

\section{Expectancy Questionnaire 2}

60

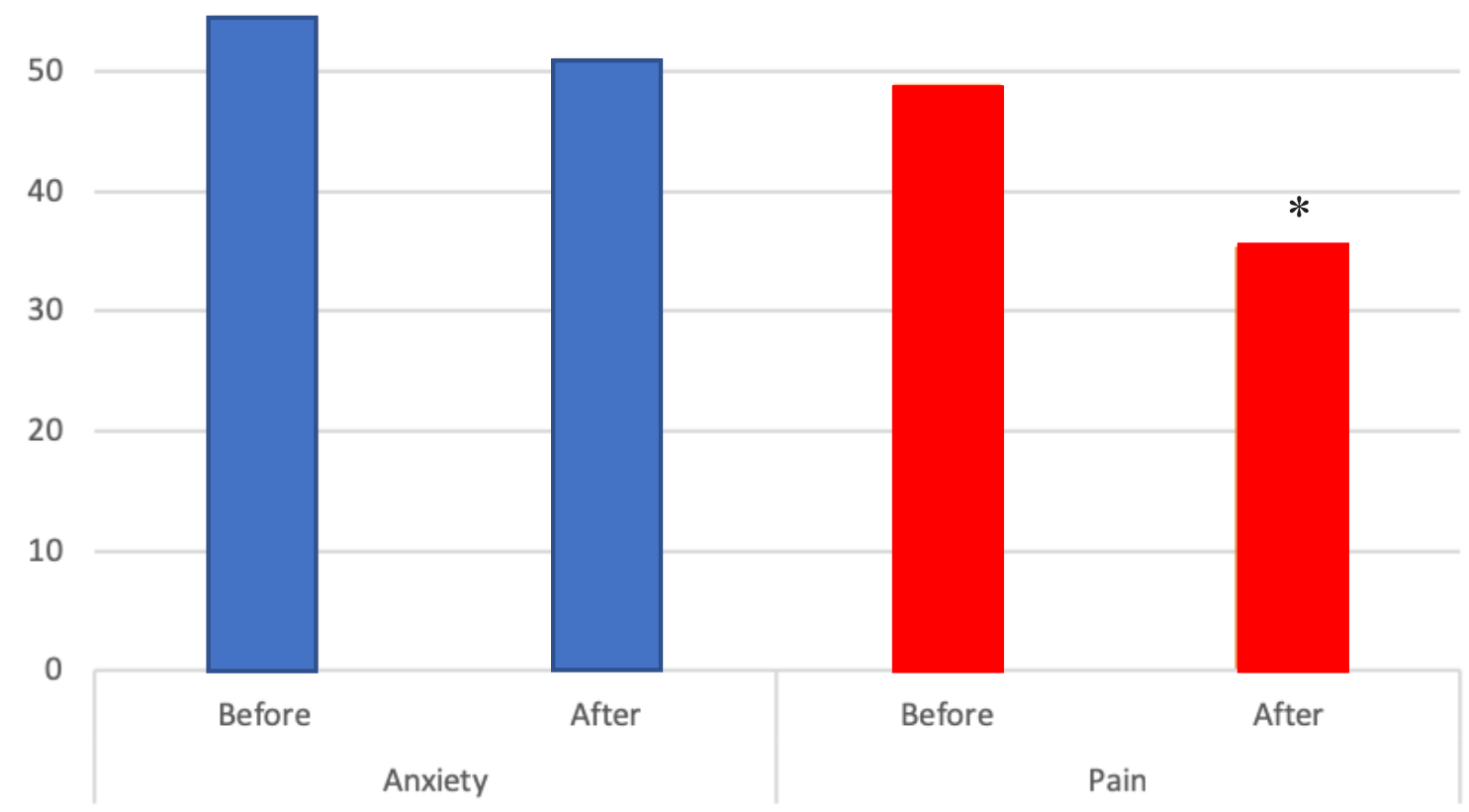

Figure 7. Expectancy questionnaire responses for anxiety and pain, obtained before and immediately after surgery. A: Question: How successful do you think aromatherapy will be/was in reducing anxiety (blue bars) or pain (red bars)? B: Question 2: By the end of this study, how much do you think your anxiety (blue bars) or pain (red bars) will/did improve? * $P=0.025$. 


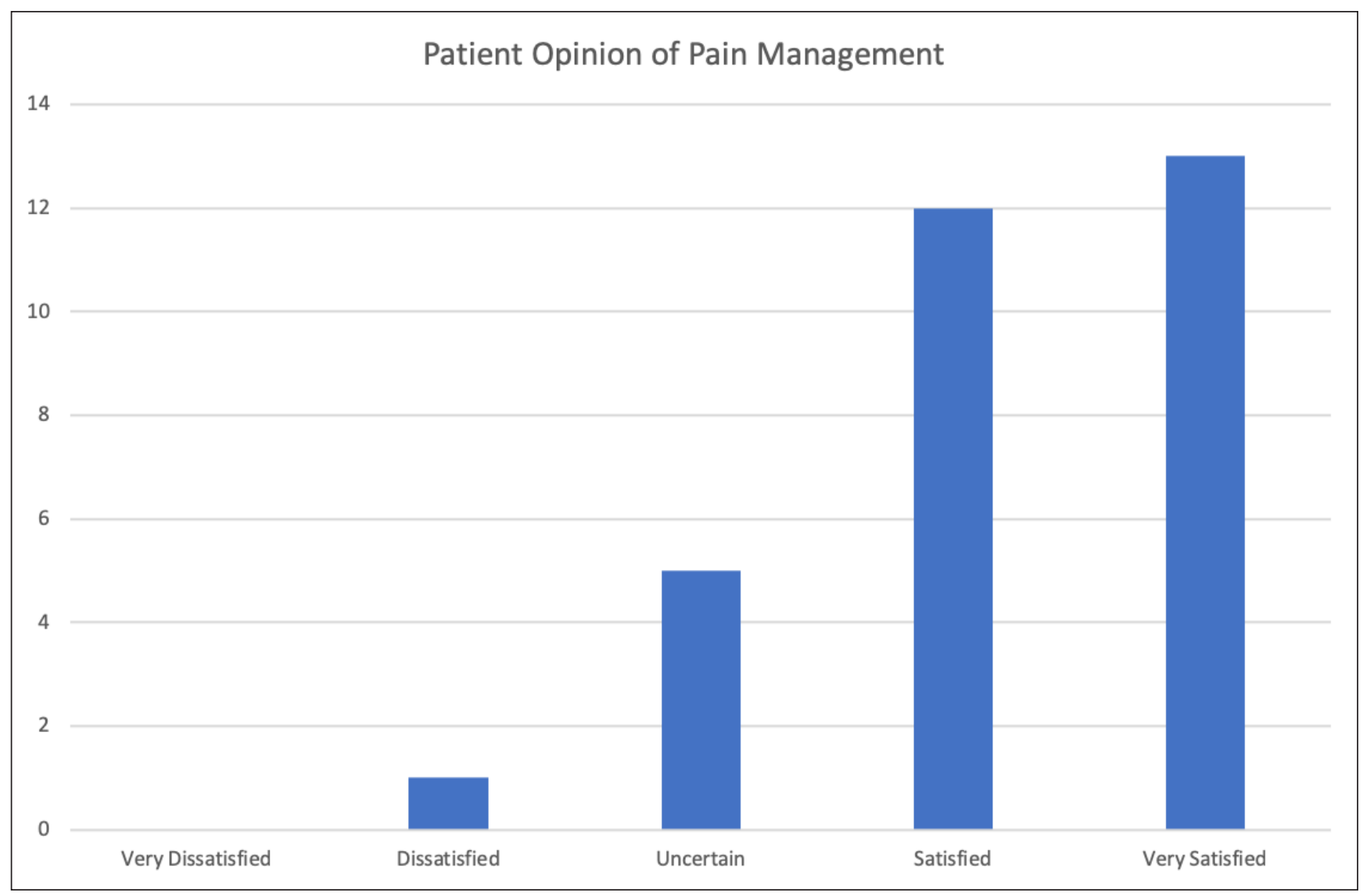

Figure 8. Patient Opinion of Pain Management survey results. Upon arrival in the neurosurgical intensive care unit, patients were asked the question: "How satisfied are you with your pain treatment overall?" Response choices were "Very Dissatisfied," "Dissatisfied," "Uncertain," "Satisfied," and "Very Satisfied."

the neurocognitive exam. ${ }^{22}$ And while most surgical patients experience a loss of control in the perioperative period, this is magnified for awake patients, as they are continuously aware of their restricted freedom of movement during the operation. ${ }^{23}$ In fact, we found a high percentage of patients wished to self-administer lavender aromatherapy, which we did not necessarily anticipate. This is an interesting finding that will be taken into consideration when designing the tools and statistical analyses for a clinical trial, as we need to know whether this impacts efficacy of lavender aromatherapy in any way.

Therefore, adoption of a new intraoperative intervention during awake craniotomy should be weighed against the imperatives of improved patient comfort and sense of control, enhanced collaboration among the surgical team, and a willing engagement by OR personnel. In this study, lavender aromatherapy performed favorably against these measures. Enrollment and satisfaction rates were high.

Previously published literature demonstrates that lavender aromatherapy has both anxiolytic and analgesic properties. ${ }^{8-15}$ Indeed, in this study there was a trend toward an anxiolytic benefit with use of lavender aromatherapy. This trend was not statistically significant, but efficacy was not the intent of this study. Additionally, awake cranial surgery in this pilot study was comfortable; baseline VAS-P and VAS-A scores were quite low, providing little room for improvement with lavender aromatherapy. There was a reduction in the improvement of pain reported by patients after surgery compared with their expected improvement 
prior to surgery, and it is unclear at this time what might have caused this change. However, this study did find that patients were willing to use aromatherapy, the technique was quite feasible, and the intervention was adopted without complaint.

Integrative medicine interventions are underutilized, and this study highlights their applicability within a complex environment such as awake cranial surgery in the neurosurgical OR. Aside from selection of music, there are limited options for patients to feel in control in the OR. The ability to exert control through lavender aromatherapy proved important, as evidenced by the overwhelming preference for aromatherapy to be delivered on request rather than on a predetermined schedule. The factor of control may indeed prove to be significant in future studies.

Limitations of this study include the fact that there is a large placebo effect for conditions such as anxiety and pain $^{24,25}$ as well as the inability to find an equivalent placebo. Furthermore, potential benefit to the patient may reside largely in their increased sense of control in self-administering the lavender aromatherapy.

Despite the limitations, these encouraging results support a larger trial that is powered to assess efficacy in the setting of awake craniotomy.

\section{CONCLUSIONS}

This study highlights the possible applications of intraoperative lavender aromatherapy during awake cranial neurosurgical procedures. Based on the percentage of patients who consented and eventually completed the study as well as the technical ability to offer lavender aromatherapy within the OR, we conclude that lavender aromatherapy was feasible and will continue to be offered to patients on an as-needed basis during awake cranial surgery. In addition, the results from this feasibility study will be used to inform a randomized trial to assess efficacy of lavender aromatherapy. We feel that using integrative medicine approaches (especially those that may increase patient control of their environment) in the context of awake cranial surgery opens novel avenues of inquiry that may benefit our patients and therefore merit continued exploration.

\section{Patient-Friendly Recap}

- Performing brain surgery while a patient remains awake carries many advantages over use of general anesthesia, but this approach can increase patients' anxiety about and during the procedure.

- The authors tested a protocol that allowed patients to receive lavender aromatherapy through an inhaler during their awake craniotomy.

-While anxiety and pain scores did not significantly improve from lavender, implementation of the aromatherapy proved feasible and was associated with positive patient satisfaction.

- Further study of lavender aromatherapy in patients having awake brain surgery is warranted.

\section{Acknowledgments}

The authors thank Gary Dennison of Aurora Health Care for expertly guiding this project through the regulatory process. The authors also thank Jennifer Jacob, PhD, of JBJ Research \& Medical Writing (Rutland, VT) for assistance in revising this manuscript.

\section{Author Contributions}

Study design: Cathey, Conway, Ames, Kassam, Rovin. Data acquisition or analysis: Gunyon, Chung, Conway, Ames, Singh, Rovin. Manuscript drafting: Rovin. Critical revision: Cathey, Conway, Ames.

\section{Conflicts of Interest}

Nancy Conway and Diane Ames are co-owners of Flora Pharmica LLC (Wauwatosa, WI), which manufactures a lavender-scented cream. No Flora Pharmica products were used for this study one.

\section{Funding Sources}

This research was supported by the Aurora Research Institute and the Aurora Health Care Foundation (Milwaukee, WI).

\section{References}

1. Khan SA, Nathani KR, Ujjan BU, Barakzai MD, Enam SA, Shafiq F. Awake craniotomy for brain tumours in Pakistan: an initial case series from a developing country. J Pak Med Assoc. 2016;66(10 suppl):S68-S71.

2. Eseonu CI, ReFaey K, Garcia O, John A, Quiñones-Hinojosa A, Tripathi P. Awake craniotomy anesthesia: a comparison of the monitored anesthesia care and asleep-awake-asleep techniques. World Neurosurg. 2017;104:679-86. CrossRef 
3. Leal RT, da Fonseca CO, Landeiro JA. Patients' perspective on awake craniotomy for brain tumors-single center experience in Brazil. Acta Neurochir (Wien). 2017;159:725-31. CrossRef

4. Danks RA, Rogers M, Aglio LS, Gugino LD, Black PM. Patient tolerance of craniotomy performed with the patient under local anesthesia and monitored conscious sedation. Neurosurgery. 1998;42:28-34. CrossRef

5. Beez T, Boge K, Wager M, et al. Tolerance of awake surgery for glioma: a prospective European Low Grade Glioma Network multicenter study. Acta Neurochir (Wien). 2013;155:1301-8. CrossRef

6. Zemmoura I, Fournier E, El-Hage W, Jolly V, Destrieux C, Velut S. Hypnosis for awake surgery of low-grade gliomas: description of the method and psychological assessment. Neurosurgery. 2016;78:53-61. CrossRef

7. Gruzelier J, Warren K. Neuropsychological evidence of reductions on left frontal tests with hypnosis. Psychol Med. 1993;23:93-101. CrossRef

8. Braden R, Reichow S, Halm MA. The use of the essential oil lavandin to reduce preoperative anxiety in surgical patients. J Perianesth Nurs. 2009;24:348-55. CrossRef

9. Franco L, Blanck TJ, Dugan K, et al. Both lavender fleur oil and unscented oil aromatherapy reduce preoperative anxiety in breast surgery patients: a randomized trial. J Clin Anesth. 2016;33:243-9. CrossRef

10. Kim JT, Ren CJ, Fielding GA, et al. Treatment with lavender aromatherapy in the post-anesthesia care unit reduces opioid requirements of morbidly obese patients undergoing laparoscopic adjustable gastric banding. Obes Surg. 2007;17:920-5. CrossRef

11. Kim JT, Wajda M, Cuff G, et al. Evaluation of aromatherapy in treating postoperative pain: pilot study. Pain Pract. 2006;6:273-7. CrossRef

12. Soltani R, Soheilipour S, Hajhashemi V, Asghari G, Bagheri M, Molavi M. Evaluation of the effect of aromatherapy with lavender essential oil on post-tonsillectomy pain in pediatric patients: a randomized controlled trial. Int J Pediatr Otorhinolaryngol. 2013;77:1579-81. CrossRef

13. Olapour A, Behaeen K, Akhondzadeh R, Soltani F, Al Sadat Razavi F, Bekhradi R. The effect of inhalation of aromatherapy blend containing lavender essential oil on cesarean postoperative pain. Anesth Pain Med. 2013;3:203-7. CrossRef

14. Heidari Gorji MA, Ashrastaghi OG, Habibi V, Charati JY, Ebrahimzadeh MA, Ayasi M. The effectiveness of lavender essence on sternotomy related pain intensity after coronary artery bypass grafting. Adv Biomed Res. 2015;4:127. CrossRef
15. Lakhan SE, Sheafer H, Tepper D. The effectiveness of aromatherapy in reducing pain: a systematic review and metaanalysis. Pain Res Treat. 2016;2016:8158693. CrossRef

16. Thabane L, Ma J, Chu R, et al. A tutorial on pilot studies: the what, why and how. BMC Med Res Methodol. 2010;10:1. CrossRef

17. Arain M, Campbell MJ, Cooper CL, Lancaster GA. What is a pilot or feasibility study? A review of current practice and editorial policy. BMC Med Res Methodol. 2010;10:67. CrossRef

18. Abend R, Dan O, Maoz K, Raz S, Bar-Haim Y. Reliability, validity and sensitivity of a computerized visual analog scale measuring state anxiety. J Behav Ther Exp Psychiatry. 2014;45:447-53. CrossRef

19. Facco E, Stellini E, Bacci C, et al. Validation of visual analogue scale for anxiety (VAS-A) in preanesthesia evaluation. Minerva Anestesiol. 2013;79:1389-95.

20. Jensen MP, Chen C, Brugger AM. Interpretation of visual analog scale ratings and change scores: a reanalysis of two clinical trials of postoperative pain. J Pain. 2003;4:407-14. CrossRef

21. Calvin A, Becker H, Biering P, Grobe S. Measuring patient opinion of pain management. J Pain Symptom Manage. 1999;18:17-26. CrossRef

22. Hansen E, Seemann M, Zech N, Doenitz C, Luerding R, Brawanski A. Awake craniotomies without any sedation: the awake-awake-awake technique. Acta Neurochir (Wien). 2013;155:1417-24. CrossRef

23. Palese A, Skrap M, Fachin M, Visioli S, Zannini L. The experience of patients undergoing awake craniotomy: in the patients' own words. A qualitative study. Cancer Nurs. 2008;31:166-72. CrossRef

24. Piercy MA, Sramek JJ, Kurtz NM, Cutler NR. Placebo response in anxiety disorders. Ann Pharmacother. 1996;30:1013-9. CrossRef

25. Colloca L, Klinger R, Flor H, Bingel U. Placebo analgesia: psychological and neurobiological mechanisms. Pain. 2013;154:511-4. CrossRef

(C) 2020 Aurora Health Care, Inc. 